\title{
Human spatial orientation in the pitch dimension
}

\author{
MALCOLM M. COHEN \\ Naval Air Development Center, Warminster, Pennsylvania 18974
}

and

CARL A. LARSON

NASA Headquarters, Washington, D.C. 20546

\begin{abstract}
Two experiments were conducted. In Experiment I, each of eight Ss attempted to place himself at 13 different goal orientations between prone and supine. Deviations of achieved body pitch angles from goal orientations were determined. In Experiment II, each of eight Ss attempted to align a visual target with his morphological horizon while he was placed at each of the 13 goal orientations. Changes in settings of the target were examined. Results indicate that Ss underestimate body pitch when they are tilted less than $60 \mathrm{deg}$ backward or forward from the vertical, overestimate body pitch when they are nearly prone, and accurately estimate body pitch when they are nearly supine. In contrast, Ss set the visual target maximally above the morphological horizon when they are tilted $30 \mathrm{deg}$ forward from the vertical. The findings are discussed in terms of common and different physiological mechanisms that may underlie judgments of these types.
\end{abstract}

Classical studies of human spatial orientation have demonstrated that perceived body position is strongly influenced by the direction of gravitational forces acting on $S$ (Aubert, 1861; DeLage, 1886; Muller, 1916). Generally, $S$ is deprived of external visual cues, is tilted from the vertical, and is required to indicate his perceived orientation in space, either by adjusting or estimating the tilt of his body directly or by adjusting or estimating the position of a visual target relative to his body. In most studies of this type, Ss have been tilted in the lateral rather than in the sagittal plane, and as a result, considerably more data are available for perceived body roll than for perceived body pitch.

Systematic errors of perceived orientation have been described both quantitatively and in detail for body tilts in the lateral (roll) plane (Bauermeister, 1964; Bauermeister, Werner, \& Wapner, 1964; Ebenholtz, 1970). Although similar errors of perceived orientation have been reported for body tilts in the sagittal (pitch) plane (DeLage, 1886; Correia, Hixson, \& Niven, 1968; Ebenholtz, 1970, 1972), detailed quantitative descriptions over a wide range of body pitch angles are lacking.

The present studies examine perceived body tilt in the pitch dimension by requiring $S$ to adjust the pitch of his body to various orientations while he is in total darkness, and by requiring him to adjust the position of a visual target to coincide with his perceived morphological horizon while he is pitched at various orientations and is simultaneously deprived of external visual cues.

\section{EXPERIMENT I}

$\mathrm{S}$ was required to adjust the pitch of his body to each of 13 different goal orientations between prone and supine while he was in a totally darkened room.

\section{Method}

Subjects. Eight men, aged 21 to 36 years, served as volunteer Ss; all were free of any apparent motor or vestibular abnormalities.

Apparatus. A motorized Stryker CircOlectric hospital bed served to position $\mathrm{S}$ at various orientations with respect to gravity (Fig. 1). Modifications to the bed included a clinometer that indicated S's orientation with respect to gravity, a biteboard assembly that served to position S's head with respect to his body, and a target arc on which a movable disk was mounted. The disk was not illuminated for this experiment, and all measurements were taken with $S$ in total darkness.

Procedure. Initially, each S was placed supine on the bed and was tightly clamped in place by the restrainer. The orientation of S's head was adjusted with the aid of the biteboard so that Reid's baseline (an imaginary plane connecting the center of the ear canals with the bottom of the orbit of the eyes) was perpendicular with the longitudinal axis of the body and aligned with the center of the target arc. The room lights were extinguished, and $S$ activated an electric motor that changed the pitch of the bed at a rate of approximately $5 \mathrm{deg} / \mathrm{sec}$.

At the beginning of each session, E set the bed in an erect position and instructed $S$ to change the position of the bed until he judged himself to be either prone or supine. $S$ indicated to $E$ when he believed that he was at the desired (goal) position, and, teading the clinometer to the nearest degree, $\mathrm{E}$ recorded the actual position of $S$ 's body. Each $S$ was given two sequences of runs in alternating 


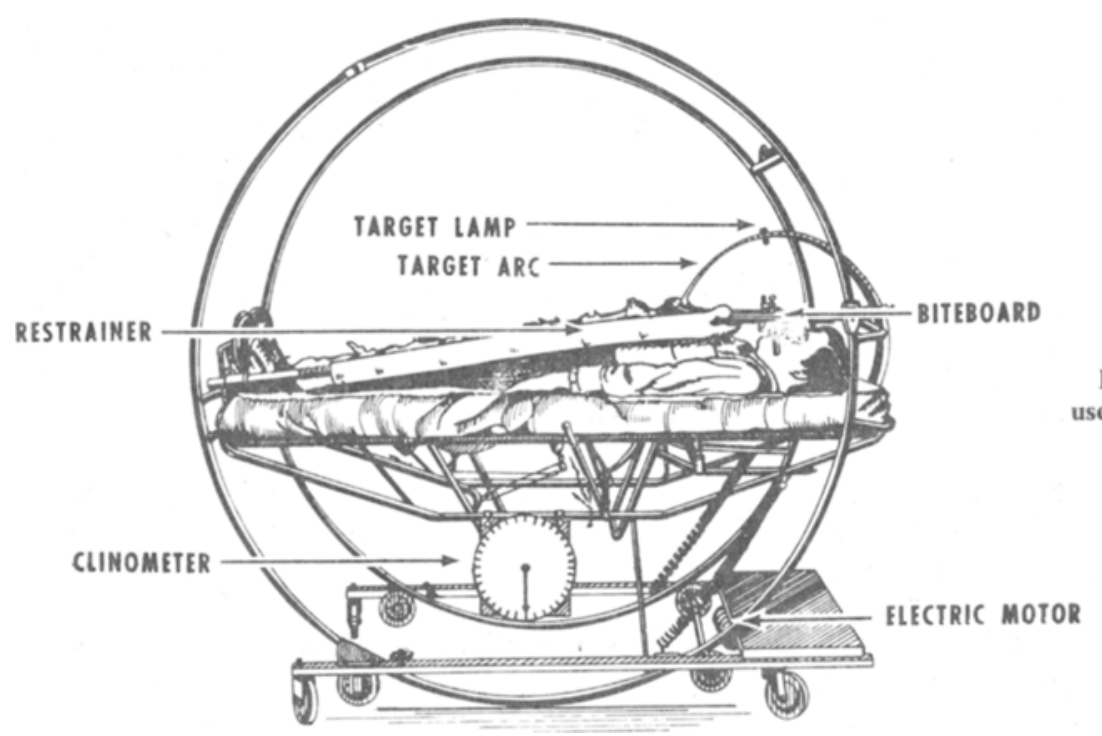

Fig. 1. Modified Stryker CircOlectric bed used in these experiments.

order. In one sequence, $S$ initially attempted to place himself in a prone ( $90 \mathrm{deg}$ forward) position, and, at increments of $15 \mathrm{deg}$, to work his way backward until he was supine ( 90 deg backward); in the other sequence, the order was reversed. All eight Ss underwent each sequence four times, yielding 64 determinations for each of the 13 goal positions.

\section{Results}

Mean settings of body position as a function of goal orientation, as computed across all sessions for all Ss, are presented in Fig. 2. The dashed diagonal line with a slope of 1.0 represents perfect agreement between perceived and objective body orientation.

Deviations of mean body position from goal orientation are depicted in Fig. 3. Positive deviations indicate that $S$ placed himself forward from the goal orientation, and negative deviations indicate that $S$

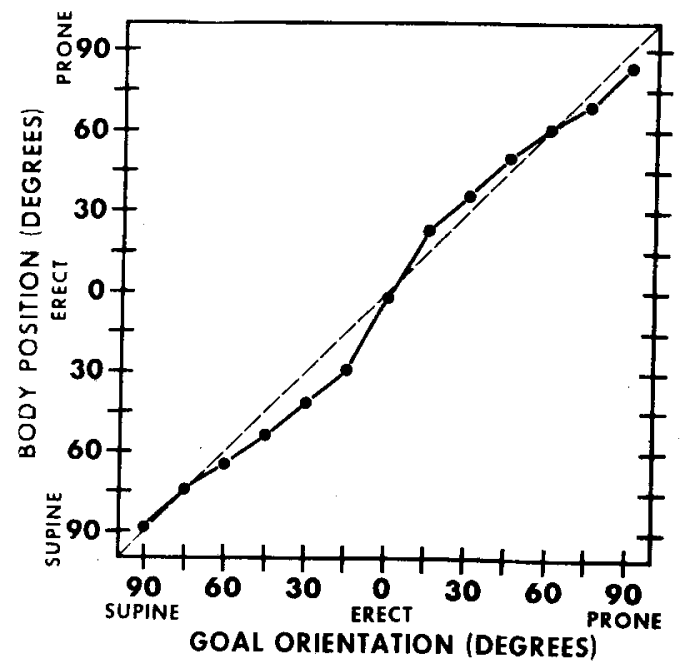

Fig. 2. Adjustments of body pitch as a function of goal orientation. placed himself backward from the goal orientation. An analysis of variance, summarized in Table 1 , shows that the deviations from the goal orientation change significantly as a function of the goal orientation.

When $S$ is instructed to place himself in a supine position, he deviates by approximately $1 \mathrm{deg}$, actually orienting himself with his head slightly forward from supine. As the goal orientation is changed, S's deviations reverse, approaching $14 \mathrm{deg}$ backward from the goal orientation when the goal orientation is 15 deg backward from erect; i.e., $S$ orients himself approximately $29 \mathrm{deg}$ backward from erect when he is instructed to place himself 15 deg backward. The deviations diminish, and, when instructed to place himself erect, $S$ actually orients himself about $2 \mathrm{deg}$

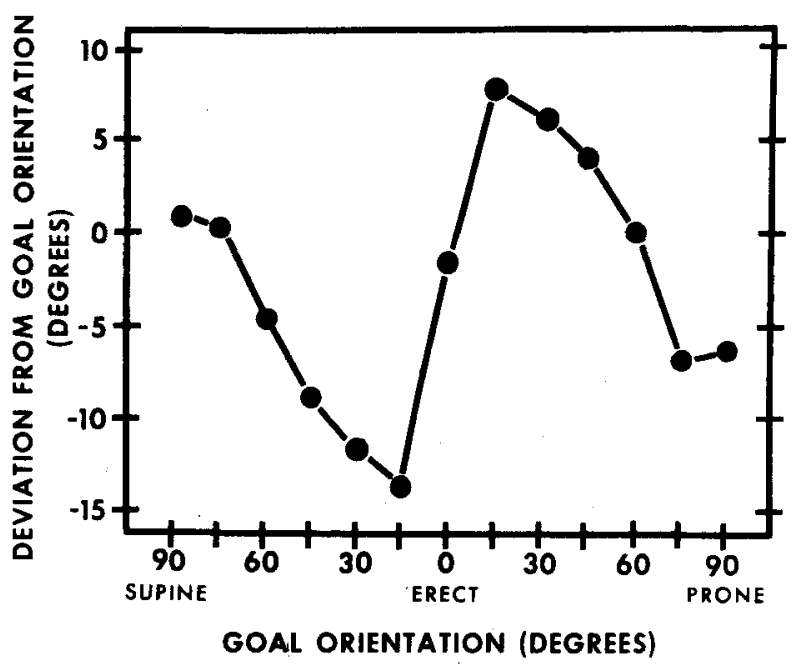

Fig. 3. Deviations of body pitch from goal orientations. 
Table 1

Analysis of Variance: Deviation of Body Position from Goal Orientation

\begin{tabular}{lrrrrr}
\hline Source & df & $\begin{array}{c}\text { Sum } \\
\text { Squares }\end{array}$ & $\begin{array}{c}\text { Mean } \\
\text { Square }\end{array}$ & F Ratio & p \\
\hline $\begin{array}{l}\text { Goal Orien- } \\
\text { tation (GO) }\end{array}$ & 12 & 4265.14 & 355.43 & $\mathbf{1 4 . 9 8}$ & $<.001$ \\
Subjects (S) & 7 & 528.43 & 75.49 & & \\
GO by S & 84 & 1993.16 & 23.73 & & \\
\hline
\end{tabular}

backward from erect. The trend continues until, at a goal orientation of $15 \mathrm{deg}$ forward, $S$ deviates in the opposite direction by nearly $8 \mathrm{deg}$, orienting himself at $23 \mathrm{deg}$ forward from erect. Again, the deviations diminish, approaching zero when the goal orientation is $60 \mathrm{deg}$ forward from erect. The trend continues, and when told to place himself in a prone position, $\mathrm{S}$ deviates by about $6 \mathrm{deg}$, pitching himself at an angle of 84 deg forward from erect.

The systematic errors of perceived body orientation are reminiscent of the Aubert (A) phenomenon and the Muller (E) phenomenon for body tilts in the lateral plane. In this experiment, however, it is clear that small body tilts in the sagittal plane are underestimated; $S$ pitches himself nearly $29 \mathrm{deg}$ backward from erect and nearly $23 \mathrm{deg}$ forward from erect when he reports himself to be pitched $15 \mathrm{deg}$ backward and $15 \mathrm{deg}$ forward, respectively. In contrast, large forward body tilts tend to be overestimated; $S$ pitches himself only $84 \mathrm{deg}$ forward when he reports himself to be prone. However, large backward body tilts are estimated quite accurately; $S$ pitches himself 89 deg backward when he reports himself to be supine.

\section{EXPERIMENT II}

$S$ was placed in a totally darkened room, tilted at each of 13 different orientations of body pitch, and asked to indicate when a visual target was perceived to be aligned with his morphological horizon, an imaginary plane that runs perpendicular to his longitudinal body axis and passes through the center of his eyes.

\section{Method}

Subjects. Eight men, aged 21 to 36 years, served as volunteer Ss. Five $S$ s served in Experiment I, and three had not participated previously. All Ss had normal visual acuity without correction, and were free of any apparent motor or vestibular abnormalities.

Apparatus. The apparatus was identical with that used in Experiment I; however, the target disk was illuminated and seryed as the manipulandum to indicate S's apparent morphological horizon. The arc, curved at a radius of $33.5 \mathrm{~cm}$ from S's eyes, was oriented in his midsaggital plane, and the target disk, $5 \mathrm{~mm}$ in diam, could be positioned by $\mathrm{E}$ at any point along the arc. The position of the target disk, which could be read by $E$ to the nearest degree, was displayed on a scale at the side of the arc.

Procedure. $\mathrm{S}$ was aligned on the bed, as in Experiment $\mathrm{I}$. The

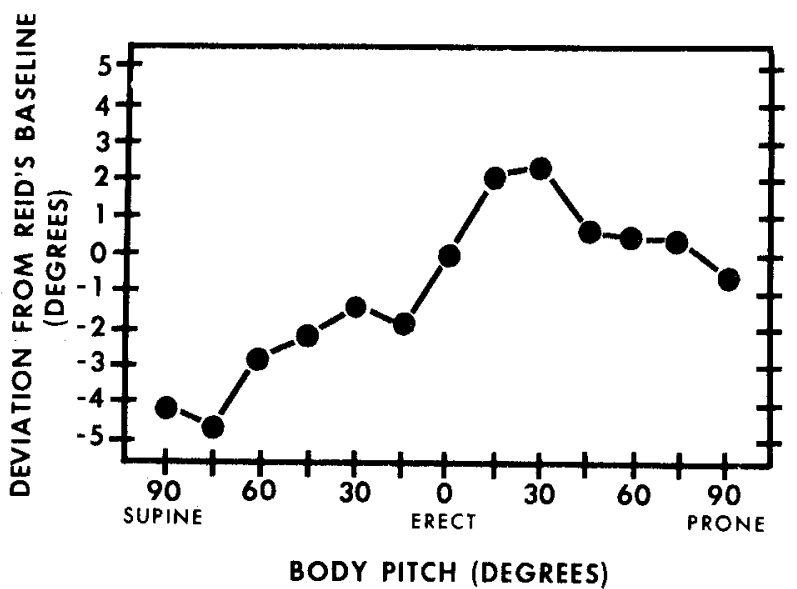

Fig. 4. Deviations of target position as a function of body pitch.

room was completely darkened, and $E$ placed the bed at an initial pitch orientation for $1 \mathrm{~min}$ before data were obtained. E illuminated the target disk and adjusted its position until $S$ indicated that it was aligned with his perceived morphological horizon. E recorded the position of the target disk, instructed $S$ to close his eyes, repositioned the disk either above or below the morphological horizon, instructed $S$ to open his eyes, and readjusted the position of the disk until $S$ again indicated that it was correctly aligned. The procedure was repeated until $S$ had provided eight estimated of his morphological horizon, four when the target disk was moved downward and four when it was moved upward. The bed was placed at a new pitch orientation, and, after a 1-min delay, additional data were collected as described above.

All eight $S$ s experienced two sessions in which data were collected, yielding a total of 128 determinations of the perceived morphological horizon for each body orientation. In one session, $\mathrm{S}$ was pitched sequentially, at increments of $15 \mathrm{deg}$, from prone to supine; in the other session, the sequence was reversed. No $S$ underwent more than one session on any given day.

\section{Results}

Mean settings of the target disk to the perceived morphological horizon, as computed across both sessions for all Ss, are shown in Fig. 4. The data are all referred to Reid's baseline, which is approximately $6 \mathrm{deg}$ below the true morphological horizon. For the data of Fig. 4, positive deviations indicate that the target was positioned above Reid's baseline, and negative deviations indicate that it was placed below Reid's baseline.

An analysis of variance, summarized in Table 2 , shows that the perceived morphological horizon changes significantly with changes of body pitch.

Settings of the target reach a maximum of $2.5 \mathrm{deg}$ above Reid's baseline when $S$ is pitched $30 \mathrm{deg}$

Table 2

Analysis of Variance: Settings of Target to Perceived Morphological Line of Sight

\begin{tabular}{lrrrrc}
\hline & & Sum & Mean & F & \\
Source & df & Squares & Square & Ratio & p \\
\hline Body Pitch (BP) & 12 & 474.80 & 39.57 & 3.92 & $<.001$ \\
Subjects (S) & 7 & 1656.84 & 236.69 & & \\
BP by S & 84 & 848.78 & 10.10 & & \\
\hline
\end{tabular}


forward from erect. Since the macular surface of the utricle slopes anteriorly upward at an angle of approximately $30 \mathrm{deg}$ from Reid's baseline (Corvera, Hallpike, \& Schuster, 1958), the macular surface is approximately horizontal when $S$ is pitched $30 \mathrm{deg}$ forward from erect. At this orientation, shearing forces along the macular surface of the utricle are minimized (Cohen, 1973; Schöne, 1964).

If shearing forces comprise the primary stimulus for the utricle (Békésy, 1966), and if decreased shearing forces result in a progressive upward displacement of the eyes (Fluur, 1970), we might expect that the target would have to be raised for its retinal projection to remain at the perceived morphological horizon, provided that retinal local signs (Bruell \& Albee, 1955) remain unchanged under these conditions. Our data are in agreement with this conjecture.

\section{DISCUSSION}

The results of Experiment I demonstrate that errors of body orientation are greatest when $S$ attempts to pitch himself $15 \mathrm{deg}$ forward and $15 \mathrm{deg}$ backward from erect. In contrast, the results of Experiment II indicate that errors in adjustments of a visual target to the perceived morphological horizon do not change in the same manner. Although $S$ is capable of adjusting his orientation in space without visual references and is also capable of adjusting the location of a visual target relative to his body, performance on the two tasks is differently influenced by body pitch. Setting the body itself to an external reference defined by the direction of gravitational forces and setting a visual target to a reference position relative to the body do not appear to be converging operations under the conditions of these experiments.

The two experiments reported here measure essentially different variables that are probably subserved by both common and different physiological mechanisms. Visual judgments of spatial locations depend not only on the orientation of the body itself, but on the orientation of the eyes in their sockets and on the loci of retinal stimulation (Bruell \& Albee, 1955). Since otolith-oculomotor reflexes alter the position of the eys in their sockets, and hence the loci of retinal stimulation (Cohen, 1973; Fluur, 1970), these reflex responses must be considered when the orientation of $\mathrm{S}$ is changed relative to the gravitational field. Adjustments of body orientation made in total darkness, on the other hand, should not depend on otolith-oculomotor reflexes. Thus, it is not at all surprising that these two experiments yield divergent results that arise from the specific dependent variable that is measured. A mathematical model, attempting to describe the interactions of physiological mechanisms that subserve judgments of these types, has recently been developed (Larson, 1973); the model considers not only utricular functioning, but saccular and oculomotor functioning as well, and a more comprehensive analysis of human spatial orientation judgments based on the application of such a model might be quite worthwhile.

An additional point should be made relating our findings to others in the literature. The results of Experiment I stand in general agreement with data reported by DeLage (1886) and with those cited by von Fieandt (1966, p. 257), but they disagree sharply with data reported by Ebenholtz (1970, 1972), which indicated a progressive overestimation of body pitch between erect and supine. Although the precise reasons for the divergence of Ebenholtz's data from the other findings cited here remain uncertain, it may be instructive to speculate on one possible cause. Ebenholtz (1970, 1972) used a Ss-within-conditions design in which separate groups of Ss were exposed to a single body tilt and, after a delay of $3 \mathrm{~min}(1970)$ or $1 \mathrm{~min}$ (1972), were required to estimate their orientations with respect to gravity. A procedure such as this might cause Ss to come to disregard tactile and proprioceptive inputs, due to adaptation of the receptors underlying these modalities, and to base their judgments predominantly on otolith organ activity, which does not appear to adlapt rapidly to prolonged constant stimulation.

Thus, additional complexities may enter into experiments on human spatial orientation. Temporal adaptation may be a critical variable, and additional research on the time course of judged body orientation may be particularly instructive in clarifying the basis for the divergent findings reported by the various investigators cited here.

\section{REFERENCES}

Aubert, H. Eine scheinbare bedeutende Drehung von Objekten bei Neigung des Kopfes nach rechts oder links. Virchows Archiv, 1861, 20, 381-393.

Bauermeister, M. Effect of body tilt on apparent verticality, apparent body position, and their relation. Journal of Experimental Psychology, 1964, 67, 142-147.

Bauermeister, M., Werner, H., \& -WAPNER, S. The effect of body tilt on tactual-kinesthetic perception of verticality. American Journal of Psychology, 1964, 77, 451-456.

BÉkÉsy, G. von. Pressure and shearing forces as stimuli of labyrinthine epithelium. Archives of Oto-Laryngology, 1966, 84, $122-130$.

Bruell, J. H., \& Albee, G. W. Notes toward a motor theory of visual egocentric localization. Psychological Review, 1955, 62, 391-400.

Cohen, M. M. Elevator illusion: Influences of otolith organ activity and neck proprioception. Perception \& Psychophysics, $1973,14,401-406$

Correia, M. J., Hixson, W. C., \& Niven, J. I. On predictive equations for subjective judgments of vertical and horizon in a force fieid. Acta Oto-Laryngologica, Supplementum 230, 1968 , 20 pp.

Corvera, J., Hallpike, C. S., \& Schuster, E. H. J. A new method for the anatomical reconsruction of the human macular planes. Acta Oto-Laryngologica, 1958, 49, 4-16. 
DeLage, Y. Études expérimentales sur les illusions statiques et dynamiques de direction pour servir à déterminer les fonctions des canaux demicirculaires de l'oreille interne. Archives de Zoologie Experimentale et Generale, 1886, 4, 535-624.

Ebenholtz, S. M. Perception of the vertical with body tilt in the median plane. Joumal of Experimental Psychology, 1970, 83, 1-6.

Ebenholtz, S. M. The constancy of object orientation: Effects of target inclination. Psychologische Forschung, 1972, 35, 178-186.

FiEANDT, K. von. The world of perception. Homewood, Illinois: Dorsey Press, 1966.

Fluur, E. The interaction between the utricle and the saccule. Acta Oto-Lanygologica, 1970, 69, 17-24.
LARSON, C. A. Otolith receptors: A mathematical description of their function. Unpublished doctoral thesis, Drexel University, 1973.

MüLleR, G. E. Über das Aubertsche Phanomenon. Zeitschrift für Simnesphysiologie, 1916, 49, 109-244.

SCHÖNE, H. On the role of gravity in human spatial orientation. Acrospace Medicine, 1964, 35, 764-772.

(Received for publication March 13, 1974; revision received July 13,1974 .) 